\title{
Effect of Chelating Agents on Copper, Zinc, and Lead Uptake by Sunflower, Chinese Cabbage, Cattail, and Reed for Different Organic Contents of Soils
}

\section{T. Y. Yeh*and C. T. Pan}

Department of Civil and Environmental Engineering, National University of Kaohsiung, Taiwan

\begin{abstract}
Phytoremediation is a green remediation technology for clean-up contaminated soils. The effect of chelant addition including EDTA, DTPA, EDDS, and citric acid on phtoextraction of metals within different organic contents of soil into sunflower (Helianthus annuus), Chinese cabbage (Brassica campestris), cattail (Typha latifolia), and reed (Phragmites communis) was investigated in this pot experiment study. The application of $5 \mathrm{mmol} / \mathrm{kg}$ EDTA and DTPA had inhibitory effects on the growth of the plants, resulting in \% reduction in biomass, respectively, compared with that in the control. However, the uptake of metal into tested plants and translocation to aerial plant parts was also demonstrated. The essential metals $\mathrm{Cu}$ and $\mathrm{Zn}$ uptake by sunflowers were significantly enhanced via citric acid addition. The other three chelants (EDTA, DTPA, and EDDS) did not improve the $\mathrm{Cu}$ and $\mathrm{Zn}$ root uptake nor above ground parts translocation compared to the control plant. The addition of $5 \mathrm{mmol} / \mathrm{Kg}$ citric acid achieved the maximum extent of phytoextraction.
\end{abstract}

Keywords: Phytoextraction; Chelating agents; Heavy metals

\section{Introduction}

Copper and zinc contaminated soils resulting from irrigation polluted by swine wastewater are one of the major environmental problems in Taiwan [1]. The contamination of soils with heavy metals is threatening human health and ecosystems. Commonly practiced soil remediation approaches such as soil excavation and dumping, soil washing/flushing are generally costly and harmful to soil properties while these traditional methods may not be feasible to regions with limited landfill space. Phytoremediaton, the use of plants for extraction of heavy metals from contaminated soils, has been viewed as one of the green remediation approaches and drawn great attention due to its low energy consumption and high public acceptance [2]. Phytoremediaton is applicable for the contaminated sites having low to moderate levels of pollutants at shallow depths, particularly feasible as a long term solution to the problem. Harvestable parts of the plants can be processed by drying and ashing to extract metals.

The success of phytoremediaton depends on the choice of plant species and metal forms retained in soils. Several options have been employed to facilitate phytoremediaton including using cheating agents to enhance metal mobility in soils and proper vegetation to translocate metals from underground tissues to aerial parts of plants. Large biomass production and accelerate metal uptake rate and translocation into aerial parts are critical factors to achieve a viable metal phytoextraction. Leaching of metal laden seepage towards the groundwater is a major problem in the application of chelant induced phytoextraction in real scale application. Future effort should focus on natural, continuous technologies using high biomass perennial plants as well as biodegradable chelants.

The application of biodegradable chelating agents might minimize the phytotoxicity and environmental problems. Non-degradable synthetic chelants such as EDTA and DTPA utilization might be limited to ex-situ operation while control of the leachates can be ensured. Less harmful organic acids and chelants such as citric acid and particularly EDDS provided environmental safe alternatives within the context of chelant induced phytoextraction.

The mechanisms of phytoremediaton for metal uptake by vegetation mainly include phytoextraction and phytostabilization. Phytoextraction refers to metal accumulation plants to extract metals from soils and concentrate them into the harvestable aerial parts while phytostabilization means metal tolerant plants to reduce the mobility of metals by leaching into groundwater. The degree of translocation from roots to aerial tissues mainly depends on the species of plants and metals, and various environmental conditions. Phytoextraction can be used in areas with medium to low levels of metal contamination, or as a final polishing step to reduce the cost and impact of other soil remediation approaches after hot spot treatment train remediation.

The metal tolerance in wetland plants seems to be different to that of dryland plants. Comparisons of populations of the wetland plant species Typha latifolia and Phragmites australis from metal enriched sites with those from non-polluted sites have shown that they were equally tolerant of metals. Tolerant populations of wetland plants have lower zinc concentrations in aboveground biomass than nontolerant population.

Wetland plants are able to grow in high metal concentrations. It has been hypothesized that wetland plants have the tolerance to heavy metals.

Chelating agents have been shown to desorb heavy metals from the soil matrix into the soil solution, and to facilitate metal translocation from roots to shoots. The effect may vary from plant and metal species. Chelating agents are frequently used to increase the bioavailability of heavy metals, thus enhancing their uptake by plants, though this may

*Corresponding author: T. Y. Yeh, Department of Civil and Environmental Engineering, National University of Kaohsiung, Kaohsiung 811, Taiwan, Tel: 8867-591-9536; Fax: 886-7-591-9376; E-mail: tyyeh@nuk.edu.tw

Received November 18, 2011; Accepted May 28, 2012; Published May 30, 2012

Citation: Yeh TY, Pan CT (2012) Effect of Chelating Agents on Copper, Zinc and Lead Uptake by Sunflower, Chinese Cabbage, Cattail, and Reed for Different Organic Contents of Soils. J Environ Anal Toxicol 2:145. doi:10.4172/21610525.1000145

Copyright: ( 2012 Yeh TY, et al. This is an open-access article distributed unde the terms of the Creative Commons Attribution License, which permits unrestricted use, distribution, and reproduction in any medium, provided the original author and source are credited. 
also decrease their biomass because of the toxicity. The fertilizing action of chelators has been reported. Chelators can mobilized soil nutrients and increase their bioavailability to the plants. The bioavailable metal content can be evaluated through the sequential extraction procedure.

Evaluation procedures for the toxic metal fractions of soils usually rely on sequential extraction to provide several soil fractions that are useful indicators of the bioavailability of metals in soils. Changes in the proportions of metal pools affected by plant uptake may provide insight into the mechanisms of metal plant uptake.

Chelating agents assisted phytoremediaton has been demonstrated as a viable treatment for the remediation of heavy metal contaminated soil and sediment. The chelant is mainly to improve the solubilization of target metals from the soil, and render the availability of plant uptake and translocation. The extent of extraction via cheating agents depends on factors, including fractionation of metals retained in soil, types of cheating agents used, and concentrations of cheating agents employed.

The use of chelating agents for enhancing phytoextration of metals has been the recent attention. EDTA (ethylene diamine tetraacetic acid), a strong chelating agent, has been most extensively studied and continue to be for soil remediation due to its strong complexes-forming ability. Recent attention has also been on the usage of biodegradable cheating agents such as EDDS (ethylene diamine disuccinate). Ethylene diamine disuccinic acid (EDDS) is a biodegradable isomer of EDTA. EDDS is naturally occurring substance in soil where is easily decomposed into less detrimental byproducts. It has the potential to be a substitute for EDTA in chelant assisted phytoremediation. EDDS can readily solubilized metals from soils. EDDS has been demonstrated to form strong complexes with metals and to be less toxic to soil microorganisms.

Treatment train remediation approaches has gained interest and has been demonstrated to be effective for mixed contaminants. Phytoremediation coupling with chelant soil washing is a viable and emergent remediation method.

Chelant induced phytoextration was developed through solubilizing heavy metals from soil and facilitating the plant uptake and translocation.

The objectives of this study aimed to investigate the effects of different chelating agents enhancing phytoextration of wetland plants and dryland plants in different organic contents of heavy metal contaminated soils. Chelant induced phytoextraction study was conducted with EDTA, DTPA, EDDS, and citric acid to determine the extent of sunflower, Chinese cabbage, cattail, and reed to uptake $\mathrm{Cu}$ and $\mathrm{Zn}$ from soil.

\section{Materials and Methods}

\section{Background soil characterization}

Soils were collected from local farmland and compost sites $\left(22^{\circ} 73^{\prime} \mathrm{N}, 120^{\circ} 28^{\prime} \mathrm{E}\right)$. Two different organic contents (low organic, $4.16 \%$ and high organic, $25.49 \%$ ) of soils were tested to investigate the metal uptake by the studied plants. Main chemical and physical properties of the tested soils are presented. The $\mathrm{pH}$ of tested soil was around neutral. The background $\mathrm{Cu}$ and $\mathrm{Zn}$ levels for tested soils were 23 and $121 \mathrm{mg} / \mathrm{Kg}$, respectively, which is around the commonly found soil metal contents in Taiwan.

\section{Plant growth experiments}

$1.5 \mathrm{~kg}$ soils were transferred to plastic pots $(\mathrm{cm}$ height and $\mathrm{cm}$ diameter). Pots were employed to test the effect of chelant induced phytoextraction. Five seedlings of tested plants were transplanted into each pot. After growing for 2 weeks, at dose of $5 \mathrm{mmol} / \mathrm{kg}$ dry weight different chelators (EDTA, DTPA, EDDS, and citric acid) were applied to soil. Plants were grown in the greenhouse with light intensity during the daytime. Temperature was controlled at $20^{\circ} \mathrm{C}$. Each pot irrigated everyday with distilled water.

\section{Analysis of heavy metal speciation}

The fractionations of $\mathrm{Cu}$ and $\mathrm{Zn}$ retained in soils were investigated by the sequential extraction techniques. Five grams of air-dried soils were placed in centrifuge tubes and subjected to a six-step serial extraction procedure. The procedure of sequential chemical extraction used in this study including a series of reagents. They are depicted as exchangeable $\left(1 \mathrm{M} \mathrm{KNO}_{3}\right)$, inorganically bound $(0.5 \mathrm{M} \mathrm{KF})$, organically bound $\left(0.1 \mathrm{M} \mathrm{Na}_{4} \mathrm{P}_{2} \mathrm{O}_{7}\right)$, Fe- and Mn-oxide bound $\left(0.3 \mathrm{M} \mathrm{Na}_{3} \mathrm{C}_{6} \mathrm{H}_{5} \mathrm{O}_{7}\right.$ $1 \mathrm{M} \mathrm{NaHCO}$ and $\left.0.5 \mathrm{~g} \mathrm{Na}_{2} \mathrm{~S}_{2} \mathrm{O}_{4}\right)$, and sulfide $\left(6 \mathrm{M} \mathrm{HNO}_{3}\right)$ forms, respectively.

\section{Heavy metal content analysis}

Soil samples before and after phytoremediation test were collected, air-dried, screen by a $2 \mathrm{~mm}$ sieve, and oven dried at $105^{\circ} \mathrm{C}$ for $24 \mathrm{~h}$. The soil samples were digested with a microwave apparatus. The filtrate and pretreated samples was followed by the measurement of an atomic adsorption spectrophotometer (AA). The macrophytes were first rinsed with DI water to remove attached soil, separated into roots, stems, and leaves, shredded and dried. The vegetation was dried in an oven at $103^{\circ} \mathrm{C}$ and digested via a microwave digestion apparatus. The metal contents of various parts of vegetation were then measured by AA.

In order to evaluate the phytoextraction potential of plants, two metal uptake parameters were calculated to enable comparisons of metal uptake/distribution and comparisons among metals. Bioconcentration factor (BCF) was then calculated as the ratio of root metal to sediment metal concentrations $\left(\mathrm{C}_{\text {roots }} / \mathrm{C}_{\text {sediments }}\right)$ while Translocation factor (TF) was expressed as leaf and stem metal to root metal concentration $\left(\mathrm{C}_{\text {stem+leaf }} / \mathrm{C}_{\text {root }}\right)$.

\section{Statistical analyses}

Statistical significance among metal contents was assessed using mean comparison test. Differences between treatment concentration means of metals were determined by Student's $t$ tests. A level of $p<0.05$ considered statistically significant was used in all comparisons. Means are reported \pm standard deviation. In addition, differences among five fractions in the sequential extraction experiment were tested with $\mathrm{F}$ statistics.

\section{Results and Discussion}

\section{Metal speciation in the soils}

The five different fractions of $\mathrm{Cu}$ and $\mathrm{Zn}$ presented in the soils. After the amendment to increase the metal contents, $\mathrm{Cu}$ concentrations in both low and high organic soils were 847 and $872 \mathrm{mg} / \mathrm{Kg}$, respectively, while $\mathrm{Zn}$ concentration in low and high organic soils were 4486 and $4393 \mathrm{mg} / \mathrm{kg}$, respectively. These metal contents were twice the regulatory standard levels listed as contaminated soils in Taiwan. The sequential extraction procedures were employed to investigate the distribution and chemical fraction of heavy metals retained in tested soils after the application of four different chelants.

The results demonstrated that $\mathrm{Zn}$ was predominant in the 
exchangeable and fraction (\% and \%), while $\mathrm{Cu}$ was predominant in the fraction bound to organic matter (\%). The residual fraction did not exceed $\%$ of the total content for both examined metals. It appeared that the whole exchangeable fraction of $\mathrm{Cu}$ and the whole fraction bound to reducible species were completely mobilized with EDTA.

The application of EDTA and citric acid could significantly $(\mathrm{P}<0.05)$ enhance exchangeable fraction of heavy metals while the residual form of heavy metals was markedly reduced by the addition of chelants.

The total metal content of both organic soils was two times more than the environmental standard in Taiwan, indicating that soil was contaminated with $\mathrm{Cu}$ and $\mathrm{Zn}$.

\section{The growth and toxicity symptoms of tested macrophytes}

The reaction of plants to chelating agents was different depending on the chelatent dose. The maximum dose determined immediate systems of chlorosis and led to plant death in $24-48 \mathrm{~h}$ from the treatment.

There were different effects according to different applications of chelating agents and the different metal tested.

No visual toxicity symptoms were observed in the plants during the whole cultivation period in the treatments without any chelant addition. Nevertheless, all chelants promoted phytotoxicity in plants.

The addition of heavy metals did not impact macrophyte yield. These results suggested that the heavy metal levels in the soil might not have been high enough to create a level of toxicity. The plant growth increased progressively with addition of citric acid. However, the high level of metal contaminated soil with the addition of organic acid did not exhibit growth impact. The macrophyte might have the ability to accumulate heavy metals without yield decline. The addition of 5 $\mathrm{mmol} / \mathrm{kg}$ of either EDTA or EDDS to soil was already enough to cause the highest reduction in plant growth.

Rice suffered severe phytotoxicity, while vetiver did not exhibit any phytotoxic symptoms after the chelant application.

Chelators addition might increase the concentration of available heavy metals in the soil, therefore, their application may affect the plant growth. $5 \mathrm{mM}$ EDDS was suitable for phytoextraction of $\mathrm{Pb}$ from contaminated soil. The actual biomass of the plant might give an indication of toxicity caused by chelant addition.

\section{Metal uptake and translocation by macrophytes}

Metals accumulation in different parts of plants decreased in the order: root $>$ stems $>$ leaves. Soil organic matter might influence the heavy metal retention in soils via forming stable complexes. Organic matter added to contaminated soils decreased metal availability to plants.

The effects of phytoextraction include the extraction of soil metals into bioavailable forms that can be taken up by plants and the enhancement of metal translocation from roots to shoots. It has been demonstrated that EDTA used for Pb phytoextraction is a relatively biologically stable chemical compounds. Chelator EDTA was capable to overcome mass transfer limitation associated with the clay fraction in soils.

The study investigated the phytotoxicity of EDDS and EDTA and concluded a similar effect concerning their toxicity to plants. The visible symptoms, such as necrosis and chlorosis, were detected under the concentration of $3.125 \mathrm{mmol} / \mathrm{kg}$ for EDDS, and the concentration of $12.5 \mathrm{mmol} / \mathrm{kg}$ for EDTA. Reduction in plant after chelant treatment might be due to the toxicity of chelant and its complexes. Citric acids are simple carboxylic acids exuded by plant roots and commonly found in rhizosphere. Simple organic acids have the potential to enhance metal mobility in soil profiles by reducing soil $\mathrm{pH}$ and forming complexes with heavy metals. The presence of the organic acids might affect heavy metal desorption, solubility, and mobility.

The results have demonstrated that zinc and copper concentrations in roots were significant higher than in leaves and stems, indicating metal immobilization in roots.

It was shown to be better at solubilizing $\mathrm{Cu}$ and $\mathrm{Zn}$ than EDTA. Contradictory result was demonstrated to indicate EDTA was much more efficient than EDDS for the enhancement of root metal uptake and root-to-shoot translocation.

The longer exposure of the tested sunflower to toxic chelant levels in the split application treatments might limit shoot biomass production. The reason might be related to the loss of assimilates from the damaged root membranes and possibly to toxic concentrations of metals accumulated in roots and shoots.

The meal extraction from soils was conducted using the cheating agents, EDTA, EDDS, DTPA, and citric acid. The extraction efficiency results was observed as the following ranking, EDDS $>$ EDTA $>$ Cit for $\mathrm{Cu}$, and EDDS $=$ EDTA $>$ Cit for Zn.

The higher extraction capability can be predicted on the basis of the stability constant of $\mathrm{Zn}$-chelant complexes $\left(\log \mathrm{K}\left(\mathrm{Zn}-\mathrm{EDTA}^{2-}\right)\right.$ $=18.00 ;\left(\log \mathrm{K}\left(\mathrm{Zn}-\mathrm{EDDS}^{2-}\right)=13.49 ;\left(\operatorname{logK}\left(\mathrm{Zn}-\mathrm{Cit}^{2-}\right)=6.06\right)\right.$ and $\mathrm{Cu}$-chelant complexes. The similar extraction results have be demonstrated by other authors. EDTA was more effective than EDDS for enhancement of metal solubilization. This result can be predicted by the higher stabilization constant of EDTA metal complexes. The fast of EDDS biodegradation might be a factor to select feasible chelant for phytoextraction enhancement.

Study was demonstrated that both EDDS and EDTA were effective in increasing the solubility of $\mathrm{Pb}$ in paint contaminated soils. Specifically, the concentration of mobilized Pb in EDDS- and EDTA-treated soils were upto four and seven times higher, respectively, compared to the control. In addition, soil properties such as $\mathrm{pH}$, soil organic matter, clay content, and redox conditions might affect the exchangeable and immobilized metal levels. Soil organic matter had significant negative effect on mobilized $\mathrm{Pb}$ in the study.

EDDS and citric acid, biodegradable complex agents, might be promising chelating agents for use as phytoextraction enhancers due to chelants such as EDTA and DTPA might pose a potential groundwater contamination problems. EDTA, DTPA, and citric acid provided shoot concentrations of $\mathrm{Cu}$ and $\mathrm{Zn}$ higher than observed in control plants. In addition, citric acid was able to induce removal of $\mathrm{Cu}$ and $\mathrm{Zn}$ from soil without increasing the leaching risk.

EDDS degrades quite fast compared to other studied chelating agents, therefore, it should schedule several applications of the chelant This approach can maximize shoot metal uptake and reduce the risk of metal leaching into groundwater.

Research has demonstrated that both EDTA and DTPA significantly increased the contents of copper accumulated in aboveground pats and roots while DTPA was not as efficient as EDTA at enhancing copper uptake. Nevertheless, neither EDTA nor DTPA caused serious negative effects on the growth of studied plants. It was 
Citation: Yeh TY, Pan CT (2012) Effect of Chelating Agents on Copper, Zinc, and Lead Uptake by Sunflower, Chinese Cabbage, Cattail, and Reed for Different Organic Contents of Soils. J Environ Anal Toxicol 2:145. doi:10.4172/2161-0525.1000145

observed that solubilized metal levels were positively related to the chelating agent concentration. Citric acid performance in the heavy metals mobilization and phytotoxicity tests was promising.

The increase of water extractable heavy metal in planted soil could be the complexing properties of soluble exudates and the solublization of microorganisms in the rhizosphere.

Many components of root exudats can serve as carbon sources for microorganisms and facilitate microbial activity. This leads to an increase in the release of organic acids, which can mobilize metals through the formation of metal complexes. EDDS was more effective than EDTA in stimulating the translocation of metals from roots to shoots.

When plants translocate metals from root tissue to aerial tissue, they are accumulated in leaves and stems. The degree of upward translocation is dependent on the species of plant, the particular metal, and a number of environmental conditions.

All chealting agents significantly enhance the metal contents in plant tissues, however, the chelants result in a sever plant biomass lost.

The dosage of chelants must high enough to mobilize retained metals in soils without being too high to cause toxicity or elevated groundwater concentrations.

The translocation factor (TF; or the relationship between shoot and root metal concentration) can be used to evaluate the capacity of a plant to translocate metals from roots to shoots. The distribution of metals within tested plants was affected by the application of chelants. EDDS was more effective than EDTA in stimulating the translocation of metals from roots to shoots.

The $\mathrm{TF}$ values indicate the rate of translocation of the metals absorbed by the root system to the aboveground biomass. Research has found that TF did not follow the same trend observed for BCF. Higher translocation was observed in $H$. annuus for copper and zinc.

If the metals were tightly bound to the soil, bioavailability and subsequent uptake might be limited. The extent of metal sorption of soil depends on several parameters including $\mathrm{pH}$, redox potential, organic matter content, clay minerals, CEC of soils, and metal species. By EDTA addition, the metal mobility was increased to enhance plant metal uptake. However, the higher concentration was toxic to the sunflower as inhibited by diminished biomass reducing the actual mass of metal accumulated.

The low level of metal uptake might be due to the short time span of this pot experiment. Longer periods might be required if the maximum uptake capacity need to be achieved. Study has demonstrated that metal distribution in the plant tested did not seem significantly affected by the application of chelants.

Although concentrations of $\mathrm{Zn}, \mathrm{Cu}$, and $\mathrm{Pb}$ in soil solutions were increased with the addition of chelants, only a small portion of metal complexes was translocated form roots to shoots.

Study was indicated that the addition of $10 \mathrm{mmol} / \mathrm{kg}$ of both nondegradable (EDTA) and biodegradable (EDDS) chelants enhanced plant $\mathrm{Pb}$ uptake the most [2]. Research was demonstrated that multi-application of chelants was effective to decrease the potential groundwater contamination compared to single application of chelants. The application of chelating agents to soil can cause in adverse effects on the plant growth due to their poor biodegradability in soil environments. The limitations might be overcome when low phytotoxic and easily biodegradable chelants are employed.

\section{Conclusions}

The phytoremediation of soils contaminated with heavy metals is becoming popular due to its green characteristics and cost effective as well as energy efficient properties.

The use of the chelants EDTA, EDDS, was effective for enhancing the $\mathrm{Pb}$ phytoextraction from a contaminated soil through the pot experiments. The application of chelants redistributed the soil $\mathrm{Pb}$ to the more bioavailable fractions, which is essential for phytoextraction enhancement.

For phytoextraction, emphasis should be focused on improved characterization of bioavailable metal pools and resupplying from less available fractions in the contaminated soils.

\section{References}

1. Yeh TY, Wu CH (2009) Pollutants removal within hybrid constructed wetland systems in tropical regions. Water Sci Technol 59: 233-240.

2. Kos B, Lestan D (2004) Chelator induced phytoextraction and in situ soil washing of Cu. Environ Pollut 132: 333-339. 